\title{
CO-OPERATION IN ENGINEERING RESEARCH BETWEEN EDUCATIONAL INSTITUTIONS AND INDUSTRY
}

A GROUP of three papers on co-operation in engineering research between educational institutions and industry was presented for discussion at a meeting of the Education. Group of the Institution of Mechanical Engineers on January 28. The first paper of the group was by Prof. E. Giffen, of Queen Mary College, London, comparing the magnitude of the co-operation in engineering research in Britain and in the United States. Estimates of the amounts of money contributed by government departments and by industry to support research in engineering departments of universities and colleges (either in general or on specific projects) showed that the expenditure in the United States is more than a hundred times the figure for Britain. Taking the facilities available for research in terms of staff and laboratory accommodation as proportional to the numbers of full-time students, it appears that, if British educational institutions were used to the same extent as those of the United States for co-operation in research with industry (including government departments), our expenditure on this work would be increased more than ten-fold.

Prof. Giffen mentioned some of the reasons for this disparity in the amount of co-operation in the two countries and suggested that the real difficulties lie in ignorance, both in industry and in the universities, of the other side's point of view, and that many of these difficulties could be cleared away by full and frank discussion by those concerned. He went on to consider the desirable upper limit to co-operation in research, taking as criterion the benefit to the teaching work of a university department; the limit is reached when the staff are doing as much research as is consistent with their continuing to take an active and effective part in teaching. Although there is evidence that the amount of co-operation in some universities in the United States has passed this limit, we in Britain have a very long way to go before we need have any fear of that.

The second paper in the group, by Mr. V. C. Davies, was concerned mainly with engineering research in technical colleges in co-operation with industry. $\mathrm{He}$ stressed the opportunities for parttime research students to investigate problems encountered in the course of their work in industry. The time that can be devoted to the work is often much greater than that spent in the college, and the rate of progress can be surprisingly fast. Mr. Davies is of the opinion that special staff are necessary to supervise research, perhaps on a part-time basis, and special care is needed in selecting suitable subjects for research from those suggested by students from industry. Many of these suggestions are concerned with development of a particular machine or component; while some are better left to industry, others can be investigated jointly, the firm providing its own staff for parts of the work and the college undertaking the more fundamental aspects.

Mr. Davies pointed out the opportunities for more sponsored research, and its benefits to both colleges and industry. The question of publication of results need not cause any difficulty. The main reason why more systematic research is not conducted by the teachers in technical colleges is their heavy load of teaching. Until recently, all such teachers were, and many are still, required to spend about twenty hours each week with students; this, with the additional time taken in the preparation of lectures and the reading of students' work, left little time for research by the conscientious teacher. Recent changes have enabled some of the larger technical colleges to reduce the amount of teaching required of the staff, and this should make a marked improvement in the opportunities for research.

The third paper, by Mr. J. H. R. Nixon, was written from the point of view of the small and medium-size organizations engaged in the manufacture of engineering equipment. The need for more research and development is becoming more widely recognized, and with it the desire for more co-operation with educational institutions. Sponsored or contract research is a suitable method for dealing with well-defined projects, with short-term or medium-term objectives, and where specific information is required which is beyond the company's resources. In many cases it is found that the investigation of such special problems requires parallel research on fundamental lines, leading to results of general interest and with wide applications.

Mr. Nixon's experience has shown that the greatest benefit is derived if a member of the firm's staff participates in the work as it proceeds. The man might be seconded to work full-time in the university; apart from the results of the particular investigation, the experience is valuable and enhances his worth on his return to his firm. But part-time participation can also be very successful, because then the man can apply the results of his research to improvements in design or production as the research proceeds. No better integration of research and development can be obtained than by organizing them to go on side by side, either by a team of workers or by a single man, depending on the nature of the project. In Mr. Nixon's opinion, firms are not sufficiently informed about the specialized facilities available to assist them with research and advice. Closer contact is desirable between industrial designers and development engineers and the staffs of universities and technical colleges. One way of achieving this is through the use of professors as consultants on plans for research and development-a method much more extensively practised in the United States than in Britain.

Dr. D. Clayton, who opened the discussion, emphasized the need for care in choosing suitable research problems as a basis for co-operation, and indeed in choosing all subjects for research students, to avoid wastage of man-power. Those concerned with new problems in industry should separate them into different categories according to the extent to which they involve fundamental work or practical techniques and then decide which could be investigated inside the organization; the others, mainly those involving fundamental studies, should be handed over to suitable university departments, establishments of the Department of Scientific and Industrial Research or industrial research associations.

Other speakers gave examples of the way in which co-operation in research has increased in recent years 
and of the benefits both to industry and to the university staff. Special mention was made of the close contact between the Ministry of Supply and university departments of aeronautical engineering and also of the Ministry's scheme for employing university teachers as vacation consultants. Suggestions were made for better methods of communicating information about the results of research, and about research in progress. Higher-degree theses are quite unsuitable for general publication, and the results should be re-written at different levels to suit the different kinds of readers to whom the results would be useful. It was suggested that abstracts of all higher-degree theses should be deposited with a central organization, such as the Department of Scientific and Industrial Research, which would bring the work to the notice of interested people.

Postgraduate courses for men in industry provide an effective research contact between industry and universities. The courses might be of long or short duration, but should include some experience in the investigation of problems relevant to the industry. On the other hand, it was pointed out that many of the students attending such courses, and indeed a large proportion of the students engaged on research for higher degrees, come from overseas countries, with the financial support of their governments, and will bring no direct benefit to industry in Britain. If industry were really convinced of the benefits of research and postgraduate courses as a training for its young engineers, it should send more of them back to the universities, either full-time or part-time ; this in itself would be a valuable method of maintaining closer contact and promoting co-operation between industry and educational institutions.

\section{AIRFLOW OVER MOUNTAINS}

A

DISCUSSION meeting was held on the subject of the "Airflow over Mountains" in the rooms of the Royal Meteorological Society on January 19. The subject poses an interesting problem in hydrodynamics, and also has implications of considerable importance to aviation; accordingly, many visitors having an interest in the aviation aspects attended. The discussion was opened by Mr. G. A. Corby, of the Meteorological Office, who gave a summary of the state of knowledge of the subject.

Stationary lenticular clouds can often be seen both over and to the lee of hills and mountains, strongly suggesting that systems of waves can be initiated in an airstream by topography. Cirrus clouds at $20,000 \mathrm{ft}$. or more, too, are believed to be due sometimes to the topography below; while over the Norwegian mountains so-called 'mother of pearl' clouds can be seen on rare occasions at some 70,000$80,000 \mathrm{ft}$. Clearly, the influence of mountains on the airflow above can be much more than an intensification of turbulence. Glider pilots have contributed much useful observational evidence of these special airflow effects, and their experience leads to a certain conception of what an atmospheric lee wave system is like. By exploiting the up currents in such waves, gliders have exceeded $15,000 \mathrm{ft}$. over hills of moderate size in Britain, while they have penetrated well into the stratosphere in the powerful wave systems of the Sierra Nevada in California. Powered aircraft also are affected by these vertical currents, which occasionally may be sufficiently intense to con- stitute a hazard. Aircraft flying over or near mountains sometimes pass through alternate regions of lift and sink; these regions may not be accompanied by any significant turbulence and, indeed, remarkable smoothness is sometimes reported. Vertical currents of a few hundred feet per minute are, apparently, quite common, while on extreme occasions smooth vertical currents exceeding $2,000 \mathrm{ft}$./min. have been encountered by aircraft in Europe.

The hydrodynamical problem of the laminar, frictionless and isentropic flow over an idealized twodimensional ridge has been studied by several workers, using perturbation theory. Prof. P. Queney confined himself to a uniform airstream, that is, one in which the static stability and wind in the undisturbed stream were constant, and found that the nature of the flow depended very much on the scele of the problem. For a very small hill, neither stability nor geostrophic forces were relevant, and his solution gave a single smooth disturbance over the hill. For a hill of a few kilometres in width, the stability became important, and a more complicated disturbance affected the flow above the hill throughout the depth of the airstream. For a large mountain ridge of about $100 \mathrm{~km}$. in width, his solutions predicted a lee wave system. On examination, this wave system proves to be mainly a horizontal oscillation about the geostrophic wind, having a long wave-length of some hundreds of kilometres. Although such waves probably occur in the atmosphere, they cannot be responsible for the vertical currents which embarrass aircraft and are exploited by gliders.

In Dr. R. S. Scorer's theoretical work, provision was made for variations of static stability and wind in the vertical. A certain function of the wind and stability proved to be a parameter of fundamental importance in the problem, and Scorer has shown that for realistic lee waves to be possible in an airstream, a decrease in this parameter with height is necessary. The condition can be fulfilled in practice by the presence of a layer of marked stability (or an inversion) at middle levels, with less stable air above, or by a substantial increase in wind with height, or by some combination of these two effects. Perturbation theory calculations for the flow of such an airstream over a mountain predict a system of lee waves which accords well with observational data. The waves have a wave-length of a few kilometres, and after attaining a maximum amplitude at some level, they die away at greater heights, sometimes slowly, sometimes quickly. An example of the theoretical streamlines calculated for a particular case is given in Fig. 1; the relevant temperature and wind profiles are indicated at the left of the diagram. Examination of the characteristics of the airstreams in which mountain waves have been encountered by aircraft shows that the conditions are consistent with those deduced theoretically by Scorer. The theory could be exploited qualitatively for the preparation of advice to aviation interests; but it would be difficult to apply the theory with any precision because of the complications of the atmosphere and of mountainous terrain in general.

Dr. J. Förchtgott, an expert Czech mountain glider pilot, has carried out a series of field investigations over several mountain ridges of Central Europe, using teams of gliders, light aircraft and special ground observations. He found that no organized pattern of airflow could be discerned unless the airstream had stable or neutral stability, and the wind direction was fairly constant with height and 